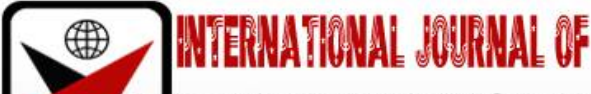

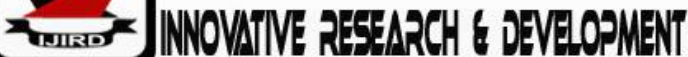

ISSN 2278-0211 (Online)

\section{How Ghanaian is Ghanaian English: A Preliminary Study from the Perspertive of a Phonetician}

\author{
John Asiegbor \\ Tutor, Department of Languages, Peki College of Educatio, Ghana \\ Clever Susuawu \\ Tutor, Department of Languages, Peki College of Educatio, Ghana
}

\begin{abstract}
:
English varies in pronunciation, grammar and vocabulary according to where one lives, the education one has received, one's past linguistic experience and the status one assumes. Because the demand of the Standard English is that people ought to use the Receive Pronunciation. This study talks about how Ghanaian a Ghanaian English is perceived from a preliminary study from the perspective of a phonetician. The main target population is senior high students precisely in Akatsi Senior High Technical School. The researcher chooses twenty students as the total population. The main focus of the study is on the selected four programmes by purposive sampling. The instrument used for the collection of data was the observation guide. The observation guide contained ten items which are the words containing some consonant sounds. It had been discovered that this study came out with the fact that Ghanaians speak English different from the way other counties speak it. This study also investigated the factors that accounted for the variations in the way Ghanaians speak English. The researcher found out that Ghanaians speak English different from the way other counties speak it and that the geographical region one stays will have influence on the way one speaks English. The study also revealed that there should be something like Ghanaian English. Based on the findings, it is suggested that since English language is a second language to the Ghanaian learner, teachers of the English language should be experts. They should have the resources of language at their disposal so that they can teach the language very well. It should not be taken for granted that anybody at all could teach the English language. The Ghana Education Service (GES) should organize inservice training for teachers regularly based on the effective use of the Received Pronunciation. More English teachers should be trained to go and teach the English language at all levels.
\end{abstract}

Keywords: Ghanaian, preliminary, perspective, phonetician, linguistic, pronunciation, variations, geographical, experts

\section{Background to the Study}

The European merchants established the castle school in Cape Coast. This establishment marked the introduction of formal education in this country. Today, however, it may not be totally correct for us to consider English as a language that is native to the few. Many people and countries all over the world have been compelled in one way or the other, by circumstances, to adopt English as a national language.

According to Graham (1978), Ghanaians came to contact with the English language first when the missionaries of English origin introduced to them formal education which started at Elmina castle in 1529. We cannot deny the fact that English language has been of immense benefit to Ghanaians.

Brain (1972) points it out obviously to Ghanaians that 'whether we like it or not, the English language has become one of the colonial legacies that has stayed with us for a very long time and would still continue to stay for a very long time in Anglophone Africa. If this is true of Africa, then it is more valid in the Ghanaian situation in which English has become a lingual Franca and a 'Unifying' factor in a country that is so richly endowed with a tapestry of ethnographic groups and languages. The English language just like any other language is an important tool for socialization. An individual or a social group can only function effectively if he has good language skills. Therefore, the English language deserves a unique place in the life of every individual.

In Ghana, English language is the medium of instruction. All subjects are taught in the English language. The curriculum materials are written in the English language. This makes the English language a compulsory subject from the nursery to the highest level of education in Ghana. Any student seeking admission or employment into any other institution of education needs to obtain a credit or pass in the English language before his application is considered. This shows how important the English language is in the academic life of literate Ghanaians.

English language plays an important role in the national curriculum so we cannot but accept the fact that the teacher of English is the pivot of the child's academic achievements and upbringing. The teacher owes a maximum duty in the academic lives of students. The teacher must help the student to acquire the linguistic repertoire the child needs to be able to fit into literate societies and to perform any office assigned to him satisfactorily. The English teacher teaches the 
four language skills such as listening, speaking, reading and writing. It has come to light through an extensive search for related literature that, much has been written about Ghanaian English but a lot needs still to be done.

\subsection{Statement of the Problem}

English varies in pronunciation, grammar and vocabulary according to where one lives, the education one has received, one's past linguistic experience and the kind of person one is. Because the demand of the Standard English is that people ought to use the Receive Pronunciation, this normally poses problem to most Ghanaians not only students but workers as a whole. The researcher has observed that the Received Pronunciation is a problem for most Ghanaians. This observation has prompted the researcher to pay particular attention to the way people in Ghana specifically Akatsi Senior High Technical School pronounce some consonant sounds in the English Language. The observation guide contained ten items which are the words containing some consonant sounds. The passage is made up of twenty key words which the researcher wants to know how these words would be pronounced by Ghanaian students in AKAST. Mainly, the factors that were indicative of questions about the pronunciations of the consonant sounds focused on the respondents' use and knowledge of the pronunciations of words regarding the Received Pronunciation. The following are the words that would be considered; coming, truth, university, news, examination, ring, stopped, walked education and think.

\subsection{Research Questions}

- How Ghanaian is Ghanaian English?

- What factors account for the variations in the speaking of the English Language?

- How can Ghanaians speak English like the native speaker?

\subsection{Purpose of the Study}

The main purpose of this study is to find out whether the Ghanaians speak English different from the way other counties speak it? This study is also to investigate the factors that account for the variations in the way Ghanaians speak English and also whether there should be anything like Ghanaian English or not. The researcher intends to find out, whether the geographical region one stays would have influence on the way one speaks English, what factors account for the variations and whether there Should be anything like Ghanaian English or not.

\subsection{Significance of the Study}

The relevance of this study is that, it will inform English teachers to realize that Ghanaians are not native speakers of the English Language and therefore could not speak it the same way the native speakers speak it. It would again inform those who may in one way or the other consider the way Ghanaians speak English Language to be deviation from the norm to accept the need to conceptualize Ghanaian English.

\subsection{Delimitation}

The study investigates only the students of Akatsi Senior High Technical School. The researcher limits the scope of his work to some selected students from Akatsi Senior High School in the Volta Region. This study is mainly limited to how students pronounced some consonant sounds in the English Language.

\subsection{Organization of the Study}

The first section is the introduction. It discusses the background knowledge, the statement of the problem, purpose of the study, research questions, significance of the study, and delimitation. It further deals with the review of related literature. Here, theories and writings of recognized authorities would be discussed. This research discusses the methodology which involves the population, sampling techniques, instrument and the manner in which the data would be collected. The fourth section deals with the analysis and discussion of the collected data while the fifth section deals with discussions, findings, conclusion and recommendation of the study.

\section{Review of Related Literature}

This section focuses on review of related literature. It deals with what other researchers or writers have found and written about Ghanaian English. This section deals with the concept of Ghanaian English. What actually makes English a Ghanaian, a perspective from a phonetician. This research discusses the issues surrounding the phenomenon of Local (or 'Nativised') Varieties of English, those developments which take place characteristically in ex-colonial territories where forms of the ex-colonial language have evolved and developed in their own right independently of their metropolitan sources. As they evolve, the issue of their acceptability often arises, and their use in classrooms will frequently cause misgivings. Add to this, the relatively common occurrence of 'code- switching' and the teacher who works in such an evolving linguistic scene is faced with decisions not only as to which language, but also which version or variety to use. Examples of local varieties are examined and their pervasiveness and usefulness are discussed. A call for policy to support teachers' practices in classrooms, complex both linguistically and socio-politically is made.

According to Dakubu, (1988), Dictionaries of indigenous African languages are prepared. They usually depend entirely on oral sources and thus no specific justification is given for entries. However, Ghanaian English is sometimes written, especially in newspapers and magazines, and thus has some sort of orthographic tradition. Previous studies in this direction have tended to cite novels or literary works these are sometimes unrepresentative of the spoken language. I have therefore used newspaper, notices and overheard speech as sources. Example sentences not specifically sourced should be treated as based on the author's or his correspondents' experiences. 
One of the more surprising things about Ghanaian English is the extent to which it has a common lexicon and grammar with other West African Englishes, notably Nigerian. Less information about Cameroun, Sierra Leone and Gambia and would welcome further insights. However, the puzzle is the history of some of these forms. Do they go back to the early days of colonial presence on the coast or are they more recent products of the massive migration of Ghanaians to Nigeria during the oil-boom era of the 1970s and 1980s? Probably both, but only a detailed scanning of earlier sources will provide answers.

Burkill (1985.), like (Dakubu 1988), hold the view that as elsewhere; the richest contributions to local English are borrowings from indigenous languages. Ghana has some fifty indigenous languages, most with only a small number of speakers. However, the major languages have millions of speakers and cultural borrowings, especially in the area of food and clothing are extensive. There are also interesting calques, whereby the structure of an expression in an indigenous language is translated word-for-word into English. The major languages are; Twi, Ewe, Ga, Hausa and Dagbane. In terms of titles Ghana has a rich heritage of traditional titles and many of the more common ones are regularly used in newspapers, for example, Asantehene. I have not listed to all of these since they are more resembling proper names. In terms of scientific names, and trade names

According to Kachru (1986), linguistically, English is prepared to express other cultures by borrowing cultureloaded words. With a considerable Romance super stratum on Germanic substratum, English is etymologically predispositioned to borrowing from foreign languages - the feature called 'hybridity and permeability' (Yano 2001: 120). 'English has done substantial pick-pocketing from other languages...' On having an option of a foreign language, many learners choose English believing that its morphology is much easier as it has few inflectional endings. The truth of the latter reason is doubtful, for any language compensates simplicity in one level by complexity in another level (in this regard, English has very intricate prepositional syntactical complexes, which present serious difficulties for English learners).

In the early colonial era, when many new species were coming to scientific attention and the uses of those known botanically were also being explored, many West African vernacular names, notably for timbers and for economic grasses. These were used in colonial literature but with a few exceptions never really entered West African speech and are rarely heard today. For example, the African olive, Canariumschweinfurthii, is called the 'bush-candle' in older literature. Charming and evocative as this name is, I have never heard it in current speech and perhaps it was only ever used by forestry officers in the colonial era. I have entered such forms sparingly, pending further evidence of their context of use. Nonetheless, there are great many names for the timbers of Ghanaian trees that are used, although in the specialized context of the timber trade. Some of these are Ghanaian, used in the West African region and some have become international trade names. I have adopted the entries from Burkill (1985.)

- $\quad$ Non-varieties of English are intelligible both within the communities in which they are used and outside these communities.

- $\quad$ The form and function of non-native varieties of English differ from native varieties.

- $\quad$ Communities that have developed institutionalized varieties of English (e.g. Ghana) should not continue to use native English models for teaching.

Literature produced by non-native speakers of English (AyiKwei Armah, Soyinka, Okara, and others) is enriching the English language.

According to OwusuAnsah (1988), the English used by Ghanaian should be recognized as a variety independent of native varieties, notably British English. The evidence is derived from the study of the form and function of English in Ghana. Until now Ghanaian scholars have been reluctant to accept the existence of Ghanaian English, either claiming that it is full of errors or denying that it is a well-developed means of communication. The paper first, refute the arguments that have been used to deny Ghanaian English legitimacy. Second, I will show that, as a result of long use, (a) Ghanaian English is now used in a wide range of contexts including informal situations and (b) it has developed into a stable system with systematic variation according to context. I will then argue that any variety that has these qualities is an institutionalized variety, which should not be regarded as a corrupt form of another (native) variety.

According to OwusuAnsah (1988), there are three arguments advanced in support of its existence. First, it is asserted that Ghanaians are conscious of the fact that their variety of English is different from other varieties, and other speakers of English are also aware that their varieties are different from the variety spoken by Ghanaians. Second, it is argued that Ghanaians have developed emotional attachment to the English language as a result of the emergence of an endonorm with its attendant sense of ownership. Third, the long period of usage has led to the expansion of the register range of the English used by Ghanaians, so that systematic variation has become a feature of this variety of English. Despite sharing some features with other varieties of English, Ghanaian English retains some characteristics that are peculiar to it.

Sey's (1973), holds the view that Ghanaian English: an exploratory survey, a title that presupposes that there is such a thing as Ghanaian English but which, in fact, denies its existence. The title of another work,Ghanaianisms: a glossary, by Kari Dako (2003), echoes the title of one of the chapters in Sey's earlier work which argues that there is no Ghanaian English but Ghanaianisms. Sey's position is that the tendency to elevate Ghanaianisms into the status of Ghanaian English by overhasty scholars is dangerous and should be resisted. This attitude earns him praise from Spencer in his foreword to Sey's work, noting that on the large issues he is not silent, but wisely tentative, modestly refuting only those who wished to rush too hastily to judgement ... and doubting the overhasty elevation of deviation through error into the dignity of Ghanaianisms.

Neither Sey's work nor any of the writings that purport to describe the phenomenon has been able to convince readers of the existence of Ghanaian English. In fact, many Ghanaians continue to deny that there is such a thing as Ghanaian English. 
This paper is concerned with issues of the identification and description of the Ghanaian variety of English. It presents three arguments in support of the existence of Ghanaian English. The first argument is based on answers to the question as to whether Ghanaians are conscious that they use the English language differently from other speakers, say Nigerians, British and Americans. The second argument hinges on the fact that over time Ghanaians have developed an emotional attachment to the English language in a way that, say, French or Japanese speakers of the English language have not. The final evidence is that English in Ghana has successfully adapted itself to its new surroundings, showing both stability and systematic variation according to context. It has developed goes without saying that they speak this variety with different non-RP accents depending on whether they came from Scotland or the USA or New Zealand or wherever.

Furthermore, there was a sizable body of published research on the validity of non-native varieties of English as a means of communication in the speech communities in which they were used; e.g. BrajKachru's The Indianness of Indian English. It is therefore clear that at the time of writing not only was Sey behind times, but he focused on stigmatised linguistic forms that no speaker of any language would like to be identified with in order to support his thesis that there was no such thing as Ghanaian English.

Second, where is the evidence that the Ghanaian speaker is disgusted by his own usage to the point that he would want to deny his Ghanaian-ness? Sey did not provide any empirical evidence in support of his claim. Contrary to this position, in 1990 a study conducted at the University of Cape Coast found that more than 65 percent of the informants who took part in it reported that they used Ghanaian Standard English as opposed to British or American Standard English. This can be taken to mean that not only were the informants aware that their variety of English was different from those of British and American native speakers, but in fact, they were not ashamed to admit that they used it.

Third, does the fact that Ghanaians feel offended when their inadequacies are brought to their attention show that Ghanaian English does not exist? Does this not on the contrary confirm that Ghanaians have developed an emotional attachment to the language?

Kachru (1982) lists emotional attachment as one of the characteristics of speakers in the Outer Circle. He explains that when English is used in a community for a long time, it becomes institutionalised, and one of the signs of this is that speakers feel emotionally attached to it. This is true of all institutionalised varieties such as Indian English, Nigerian English and Jamaican English. On the other hand, in places where the English language is a performance variety, there is no emotional attachment to it on the part of the speakers. This may be the result of the noticeable absence of historical links such as in the case of Francophone African countries like the Ivory Coast or European countries like Portugal where, although diplomatic relations with England date back many centuries, the English language has never played an important role in that society.

The reason why speakers of institutionalised varieties feel offended by being made conscious of their 'errors' is that they have developed endonorms. Endonorms, which come together with a sense of ownership of the language, are norms of usage that have been developed within the community that uses them rather than norms originating from outside that community. The latter, called exonorms, are characteristic of performance varieties of English, where there is neither emotional attachment to English is nor a sense of ownership on the part of the speakers.

Furthermore, some of the forms labelled errors are used by well-educated Ghanaian speakers, e.g. 'small chops' is stigmatised by

Nimako (2004), prefers 'savouries', even though they refer to different things. In the same way, at page 139, he ridicules 'bush meat' and suggests replacing it with 'game meat'. In the first place, the form 'game meat' is rare in nativespeaker usage, 'game' being the usual form. In addition, the cultural connotation of game being the meat of animals hunted for sport is not appropriate in the Ghanaian context where hunting for bush meat is anything but sport. Clearly, prescriptions based on a limited knowledge of native English usage and the culture underpinning it is inappropriate.

Talking about the Uniqueness of the English used by Ghanaians, the existence of Ghanaian English is denied by scholars who question the uniqueness of Ghanaian English. In his paper 'How Ghanaian is Ghanaian English',

Ahulu (1994) tries to prove that what is referred to as 'Ghanaian English' is not different from other varieties of non-native varieties, and considers this to be a stumbling block to recognising the existence of this variety. In other words, his thesis is that since Ghanaian English shares common features with Indian and Nigerian English, one cannot claim that it is an independent variety.

This line of reasoning ignores some basic issues regarding the identification of languages and dialects. The first of these is that in distinguishing one language from another, one of the most important considerations is that the people who speak the two languages consider the languages to be different regardless of whether they are linguistically different or not. A classic example is provided by German and Austrian, which are considered to be separate languages, although they are almost identical.

Hudson (1980) also cites the example of Scandinavian languages, excluding Finnish and Lapp. There is also the issue of varieties of the same language sharing common features, a phenomenon known as mutual intelligibility. Thus, American English shares very important features with British English and yet there is no difficulty in regarding them as two separate Englishes. The reason for this is partly because Americans see themselves as speaking a different kind of English, sometimes called American, but also because the two varieties constitute different standards. Another factor is the dominant position of America in the geopolitics of the world rather than linguistic differences between American and British varieties of English.

In the same way, the fact that Ghanaian English shares common linguistic features with other varieties of nonnative English cannot prevent us from considering them to be different and independent of each other.

Achebe's view of the new English being in communion with native-speaker varieties referred to the above is relevant here. The fact is that all varieties of English have something in common. Even so Ghanaian speakers are conscious of the fact that 
the English they use is different from the varieties used by British, American and indeed Nigerians and Indians. It is not only Ghanaians who recognise that they use a different variety of English; speakers of other varieties of English also recognise that their varieties are different from that of Ghanaians. A survey carried out in Edinburgh by Owusu-Ansah confirmed that British speakers noticed that Ghanaian speech was different from Nigerian speech after listening to playbacks of recordings of a mixed panel of Ghanaian and Nigerian scholars. In addition, the informants noted that both varieties were different from British speech.

The claim of any variety of English to being an independent and viable means of communication that has come of age ought to rest on whether it has developed a wide range of contextual styles called registers. In this section we ask the question, 'Is there significant and systematic variation in the English used by Ghanaians? It is argued in this paper that educated Ghanaians such as university students, who provided the data on which this section of the paper is based, are capable of using English to distinguish different contexts of situation into a new English which Achebe in 1965 described as a variety still in communion with the ancestral home, because it retains some of the characteristics of the original language.

For a long time, there have been many attempts, both directly and indirectly, to deny the existence of Ghanaian English. One of the instruments of denial is ridicule.

Kofi Sey (1973, p. 10), for instance claims: Nothing disgusts an educated Ghanaian more than to be told that the English he uses is anything but standard. The linguist may be able to isolate features of Ghanaian English and describe them. But once these are made known to him, the educated Ghanaian would strive to avoid them altogether. The surest way to kill Ghanaian English, if it really exists, is to discover it and make it known. This claim needs to be interrogated. First, what is the nature of the features that disgust the Ghanaian speaker? Indeed, throughout his book, Sey equates Ghanaian English with errors, and isolates his stages of bilingualism on the basis of errors rather than proficiency. For example, he describes stages one and two as having errors of immaturity (p. 16). He also uses the word 'peculiarities' to describe aspects of Ghanaian usage without identifying these, but in the passage quoted above, he implies that Ghanaian English is a non-standard variety.

In thus treating Ghanaian English as a non-standard variety, Sey and likeminded scholars like Gyasi (1990), Ahulu (1994) and Nimako (2004) betray conservativeness of essentialist thinking. Such a thought pattern holds that there is only one valid standard of English; that is a native speaker standard. For Sey, this is British English, with Received Pronunciation as its spoken form. That this was no longer the dominant view in English studies at the time Sey's work came out can be shown by the fact that Randolph Quirk ten years before the publication of Ghanaian English had broadened the notion of standard English to include regional varieties and, in fact, non-native varieties as well (Quirk, 1962). Trudgill (1999: 117) clarifies this issue thus:

Standard English speakers can be found in all English-speaking countries, and it is not difficult to see that no individual can use language in the same way all the varieties of English, so we just do not know how suitable they are as framework for the job.

Halliday's register theory on the other hand, is a descriptive framework that has been applied to such varieties of English. In providing guidelines on how one might recognize an institutionalized variety of English, Kachru (1982) mentions that such a variety should have a wide range of registers, thus acknowledging the influence of register theory on his work. The term 'register', as first used by Reid (1956), refers to situational variation. Halliday is responsible for elaborating the theory and firmly establishing it in linguistics. According to him, registers are varieties according to use established along three situational dimensions, namely, (a) medium, (b) subject matter, and (c) social and interpersonal relations. Corresponding to these are three linguistic patterns called mode, field and formality, respectively (Halliday, et al., 1964; Halliday and Hasan, 1976; Halliday, 1985 and Halliday and Matthiessen, 2004). More recently, Biber and Conrad (2009) have studied registers extensively with the result that our knowledge of the subject has been greatly expanded; for example, we now know that the registers in a language change over time, an observation which vindicates Kachru's citing of expanded register range as an important outcome of nativization.

In introducing the register criterion in the analysis of non-native varieties of English, Kachru broke with the tradition of seeing non-native varieties as error-riddled means of communication or imperfect versions of native varieties of English. Instead of being limited by the search for the shortcomings of non-native varieties, research can now pose new questions. Instead of asking 'How many or what type of errors do Ghanaian speakers make?' we can now ask 'How do Ghanaians adjust their language to situations?' or 'In what ways does English complement the local languages?' or 'How have the local languages affected the English language?' and so on. Answers to these questions now provide the materials for reconstructing the new image of these varieties, with their capacity to serve communicative functions as the cornerstone of this construction. This is no less than a paradigm shift in the study of non-native varieties.

An investigation into variation in the use of the English language by Ghanaians is concerned with answering the following questions:

- Does the English used by Ghanaians show systematic variation?

- What is the nature of the variation?

- What does the variation tell us about the status of the English used by Ghanaians?

The emphasis of the first question is on systematic variation, because language use is prone to variation as already established, so it is only systematic, and not random, variation that can constitute evidence of a variety that has come of age. In the case of the second question the nature of the variation draws attention to the linguistic features involved in variation as well as the statistical dimension of the investigation. Thus, a valid answer to the question necessarily has to be qualitative as well as quantitative. The third question was expected to yield the answer that the English used in Ghana is characterized by the paradox of stable variation time. It is even asserted that the same sound cannot be pronounced in the 
same way twice by the same speaker. This Heraclitian quality of language was noted by Abercrombie (1964) many years ago. If this is accepted, then it is not difficult to see that members of a speech community cannot be reasonably expected to use language in exactly the same way, either from one person to another or from one speech situation to another. Hence in discussing variation as an indicator of independence of Ghanaian English, the emphasis is not on variation per se, but on significant and systematic variation rather than on random variation.

Many functional approaches to the study of language have been proposed as frameworks for studying language variation. One of the earliest of these is the one developed by

Jakobson (1960). He identified six so-called 'constitutive factors' in the speech event, each of which gives rise to a different verbal structure when it is the focus of the communicative event. These are the addresser, addressee, context, message, contact, and code.

Another well-known model for describing linguistic variation is that of Martin Joos (1962). He isolated five styles referred to as the five clocks. These are frozen, formal, consultative, casual and intimate. From the field of ethnography of communication, Del Hymes has proposed a framework called SPEAKING, which is an acronym formed from key components of the speech situation, namely, setting, participants, ends, act sequences, keys, instrumentalities, norms, and genres. Mention must also be made of Labov, who pioneered sociolinguistic investigations of style based.

\section{Methodology}

This section deals with the setting, the methodology of the study and briefly talks about the population, sample and sampling procedure, the research instrument, the administration of the instrument, limitation of the study and data analysis procedure.

\subsection{Setting}

The researcher chooses twenty students as the total population. Ten of them are boys while ten are girls. They are' Dziekpor Richhard, Nudokpo Francis, Tugbenyo Raphel, Amenyo Daniel, Katey James, Kugbe Dzidzorli, Agbovi Ephraim, Adzaho Benard, Ahanogbe Bright, Anyidoho David, Adetu Rebecca, ApedoOphilia, Sepenu Christable, Aba Amenenyo, Agbolosu Rose Mary, Lumor Gifty, Atisu Gloria, Akpalu Rebecca,Davor Mary and Dzakpata Rejoice.

Talking about a brief educational background of each of the participants, Dziekpor Richhard attended Wisdom Preparatory school from the pre-school period to the Junior Secondary school level. He indicated the he was attending Anlo Senior High School for a year and came back to Akatsi Senior High Technical School purposely to read Business course.

Considering Nudokpo Francis, he attended AKATSICO Demonstration School from the pre-school period to the Junior Secondary school level. He indicated that he was attending school at Togo before he came back to Ghana.

TugbenyoRaphel, narrated that he attended R C. Basic School from the pre-school period and presently at Akatsi Senior High Technical School. He further indicated that, their teachers usually had the time for them during their final year in their basic level and that nobody was allowed to speak vernacular in the school.

Amenyo Daniel, attended AKATSICO Demonstration School from the pre-school period to the Junior Secondary school level. KateyJames, narrated that he attended R C. Basic School from the pre-school period and presently at Akatsi Senior High Technical School. KugbeDzidzorli made it known to the researcher that due to the financial status of his parents, he was not regular at school and that he had to move from Accra to the village to continue his education.

Agbovi Ephraim attended his basic school in Tema. According to him, some white men taught him not only English but other subjects. Ahanogbe Bright attended his basic school in Accra and according to him, they were taught by some retired teachers. Anyidoho David like AdetuRebecca, narrated that they attended preschool and their basic school at Ho E.P. basic schools and presently, she is in Akatsi Senior High Technical School.

ApedoOphilia said that she did not attend preschool but attended only basic school in Wudome L.A. basic school. According to her, because there were only few teachers, most of the times, basic four to basic six had to be combined in one classroom and in the Junior High level, during English periods, they had to read only the textbooks themselves because the Headmaster is at the same time their English teacher.

SepenuChristable made it known to the researcher that due to the financial status of his parents, she was not regular at school and that he had to move from Accra to the village to continue his education. Agbolosu Rose Mary, informed the researcher that she attended Anyako L.A. basic school and presently she is in Akatsi Senior High Technical School. She indicated that usually she attended holiday classes in Accra as she normally spent the holidays with his grandfather at Tema.

Lumor Gifty like Dzakpata Rejoice indicated to the researcher that they attended private preschool and basic schools in Accra and were taught by university graduates. As of now, they are in Akatsi Senior High Technical School. Atisu Gloria said that she did not attend preschool but attended only basic school in Wudome L.A. basic school. According to her, because there were only few teachers, most of the times, basic four to basic six had to be combined in one classroom and in the Junior High level, during English periods, they had to read only the textbooks themselves because they did not have any English teacher. Akpalu Rebecca, narrated that she attended R C. basic school from the pre-school period and presently, she is at Akatsi Senior High Technical School, Davor Mary informed the researcher that she attended Wetah L.A. basic school and presently she is at Akatsi Senior High Technical School. She indicated that usually she attended holiday classes in Accra as she normally spent the holidays with his uncle. 


\subsection{Population}

The main target population is senior high students precisely in Akatsi Senior High Technical School. There are a lot of courses that are studied in Akatsi Senior High Technical School but the researcher chooses students from only four main programmes such as General Arts, Home Economics, Business and General Science. The researcher chooses twenty students as the total population. Ten of them are boys while ten are girls.

\subsection{Sample and Sampling Procedure}

Though there are a lot of programmes in the school, the main focus of the study is on the selected four programmes by purposive sampling, the researcher is sure that students in the school reading courses are selected by the researcher to find out how students reading these courses pronounce some consonant sounds in the English Language. A random sampling method was used to select twenty students from the four programmes of study.

\subsection{The Research Instrument}

The instrument used for the collection of data was the observation guide. (Appendix A). The observation guide contained ten items which are the words containing some consonant sounds. These words are mixed with other words in a passage to be given to the participants to read. The passage is made up of ten key words which the researcher wants to know how these words would be pronounced by Ghanaian students in senior high schools precisely AKAST. Mainly, the factors that were indicative of questions about the pronunciations of the consonant sounds focused on the respondents' use and knowledge of the pronunciations of words regarding the Received Pronunciation. The following are the words that would be considered; coming, truth, university, news, examination, wring, stopped, walked education and think.

\subsection{Data Collection Procedure}

The observation guides were administered by the researcher himself. Permission was sought from the head of the school selected before the observation guides were administered to the students. In the school, the researcher explained the purpose of the study to the students after which copies were given to them to respond to. The readings were done in such a way that students do not communicate to one another how the words should be pronounced. The researcher did the recordings of the twenty students one by one as he calls them into the class. Despite certain problems encountered, it is worth mentioning that most of the respondents were very helpful, receptive and co-operative.

\subsection{Data Analysis Procedure}

The data collected was coded, by giving them letters such as A, B, C...J for easy description, analyzed statistically and interpreted in tabular form. Owing to the categorical nature of the data, the main statistical technique used was percentages.

\section{Discussions and Findings}

This section deals with the presentation and analysis of data obtained from the respondents and summary. The analysis is organized regarding the hypothesis and on the respondent's knowledge and use of the pronunciations of consonant sounds.

\begin{tabular}{|c|c|c|c|c|}
\hline Words & Correct pro. & percentage & Deviant pro. & Percentage \\
\hline Ring & 4 & 20 & 16 & 80 \\
\hline Stopped & 2 & 10 & 18 & 90 \\
\hline Education & 6 & 30 & 14 & 70 \\
\hline Think & 10 & 50 & 10 & 50 \\
\hline Walked & 6 & 30 & 14 & 70 \\
\hline Truth & 2 & 10 & 18 & 90 \\
\hline Coming & 8 & 40 & 12 & 60 \\
\hline University & 4 & 20 & 16 & 80 \\
\hline News & 6 & 30 & 14 & 70 \\
\hline Examination & 4 & 20 & 16 & 80 \\
\hline
\end{tabular}

Table 1: A Chart Showing the Distribution of How Some Consonants Sounds Were Produced by Students

\subsection{Discussion}

Twenty copies of observation guides were administered to only the students in some selected classes in AKAST. The total number of the observation guides were completed and collected. This constitutes hundred percent (100\%) response to the number of respondents targeted.

The above table indicates the following;

- The number of students who pronounced the word 'coming' with a deviant ending are very few, It can therefore be concluded that as the students who pronounce the word 'coming' in a way which breaches the code of the standard English or the received pronunciation, are more than those who pronounced it correctly, the tendency of claiming that Ghanaian English exists is an undeniable fact.

- In a similar way, the number of students who pronounced the word 'truth' with a deviant ending are very few, It can therefore be generalized that as the students who pronounced the word 'truth' in a way which violates the 
code of the standard English or the Received Pronunciation, are more than those who pronounce it correctly, then one can hold the view that the geographical position in which one comes from is a factor that influences the way in which one pronounces words.

- In the situation of the pronunciation of the word 'university', the number of students who pronounced the word 'university' with a deviant beginning are very few, an implication can therefore be attained and generalized that as the students who pronounce the word 'university' in a way which violates the demand of the standard English or the received pronunciation, are more than those who pronounced it correctly, the tendency of claiming that the place in which one comes from is a factor that influences the way in which one pronounces words.

- Talking of the pronunciation of the word 'news', the number of students who pronounced the word 'news' with a deviant ending are very few, It can therefore be generalized that as the students who pronounced the word 'news' in a way which violates the code of the received pronunciation, are more than those who pronounce it correctly, the tendency of claiming that the place in which one comes from is a factor that influences the way in which one pronounces words.

- In the analysis of the pronunciation of the word 'examination', the number of students who pronounced the word 'examination' with the correct beginning are very few, It can therefore be generalized that as the students who pronounced the word 'examination' in a way which violates the code of the standard English or the Received Pronunciation, are more than those who pronounced it correctly, then there is the tendency of claiming that the place in which one comes from is a factor that influences the way in which one pronounces words.

- The number of students who pronounced the word 'ring' with a deviant ending are very few, It can therefore be concluded that as the students who pronounce the word ' wring' in a way which breaches the received pronunciation, are more than those who pronounce it correctly, the tendency of claiming that Ghanaian English exists is an undeniable fact.

- Likewise, the number of students who pronounced the word 'stopped' with a deviant ending are very few, It can be generalized that as the students who pronounce the word 'stopped' in a way which violates the code of the standard English or the Received Pronunciation, are more than those who pronounce it correctly, then one can hold the view that the geographical position in which one comes from is indeed a factor that influences the way in which one pronounces words.

- In the situation of the pronunciation of the word 'education', the number of students who pronounced the word 'education' with the correct pronunciation are the same as those who pronounced it in a deviant way, It can therefore be generalized that as the students who pronounce the word 'university' in a way which violates the code of the demand of the standard English or the Received Pronunciation, are more than those who pronounced it correctly, then it is possible to conclude that the place in which one comes from is a factor that influences the way in which one pronounces words.

- In the situation of the pronunciation of the word 'walked', the number of students who pronounced the word 'walked' with the ending correctly are very few, It can therefore be generalized that as the students who pronounce the word 'walked' in a way which violates the code of the standard English or The Received Pronunciation, are more than those who pronounce it correctly, then one can claim that the place in which one comes from is a factor that influences the way in which one pronounces words.

- Finally, the pronunciation of the word 'think', the number of students who pronounced the word 'think' with a deviant beginning are very few, It can therefore be generalized that as the students who pronounced the word 'think' in a way which violates the code of the standard English or the received pronunciation, are more than those who pronounce it correctly, then one can hold the view that the place in which one comes from is a determining factor that influences the way in which one pronounces words.

\section{Summary, Recommendations and Conclusion}

\subsection{Summary}

This section briefly talked about the summary of findings, implications or recommendations and finally, the conclusion drawn from the findings. It had been discovered that this study came out with the fact that Ghanaians speak English different from the way other counties speak it. This study also investigated the factors that accounted for the variations in the way Ghanaians speak English. The researcher found out that Ghanaians speak English different from the way other counties speak it and that the geographical region one stays would have influence on the way one speaks English. The study also revealed that there should be something like Ghanaian English.

\subsection{Recommendation}

In view of the above findings, the researcher has found it very necessary to come out with certain recommendations that would help improve effective and efficient teaching and learning of English Language not only at the senior high levels but at all levels in general. Based on the findings, it is suggested that since English language is a second language to the Ghanaian learner, teachers of the English language should be experts. They should have the resources of language at their disposal so that they can teach the language very well. It should not be taken for granted that anybody at all could teach the English language.

The Ghana Education Service (GES) should organize in-service training for teachers regularly based on the effective use of the Received Pronunciation. The curriculum materials should be organized demanding the use of the Received Pronunciation. More English teachers should be trained to go and teach the English language at all levels. 
Finally, the researchers hope to suggest that similar study could be carried out or conducted so as to come out with effective use of the Received Pronunciation and the possible solutions to solve the problem that hinder teaching the Received Pronunciation in schools.

\subsection{Conclusion}

This research successfully came out with some significant factors which affect the use of the Received Pronunciation in senior high schools. These factors include; limited number of teachers of the English language, lack of curriculum materials such as textbooks and instructional materials regarding the use of the Received pronunciation, inadequate time given to the English language on the time table, lack of in-service education on how to maser the teaching of the received pronunciation and finally, lack of motivation of teachers. It is the researcher's hope that the suggestion made if they are taken into consideration, it will be of immense help in the enrichment of the teaching of the English language regarding the use of the Received Pronunciation.

\section{References}

i. $\quad$ Ahulu, S. (1994). How Ghanaian is Ghanaian English? English Today, vol. 10, 1, 25-29.

ii. Biber, D., and S. Conrad (2009). Register, Style and Genre. Cambridge: Cambridge University Press.

iii. Dako, K. (2003) Ghanaianisms: a glossary. Accra: Ghana Universities Press. effects of formality on the English

iv. Graham C.K (1989). The History of Education in Ghana

v. Halliday, M. (1985). An Introduction to Functional Grammar. London: E. Arnold.

vi. Halliday, M. and R. Hasan (1976). Cohesion in English. London: Longman.

vii. Halliday, M., McIntosh and P. Strevens (1964). The Linguistic Sciences and Language Teaching.London: Longman.

viii. Jakobson, R. (1960). Linguistics and Poetics. In Language and Literature, edited by Krystyna Pomorska and Stephen Rudy, 62-94.2, part v.

ix. Kachru, B. (1959). The Indianness of Indian English. Word, vol. 21, 3, New York Linguistic Circle.

x. Nimako, A. (2004). Mind your Language: Educated Ghanaian English. Tema: Ronna Publications.

xi. Sey, K.A. (1973). Ghanaian English: An exploratory survey. London: Macmillan.

xii. Trudgill, P. (1999). Standard English: what it isn't. In Standard English: the widening debate, edited by Tony Bex and Richard. Watts, London: Routledge, 117-128.

\section{Appendix}

\section{A Texrt for Reading Aloud}

I think education is the key to national development. I could remember that I walked for a long distant and stopped after the shadow of trees when I was attending school. During examination periods, when they ring the bell to start work, I felt happy because I was intelligent those days. A time would come when I would be coming to tell the news of how I attended basic school up to the university level to my students.

\section{The Deviant Ways Some Students Read The Targeted Words}

I think/ tink /education/ edukei ${ }^{\text {¡ }} \mathrm{n}$ / is the key to national development. I could remember that I walked / $\mathrm{w}^{\mathrm{s}}$ :lked / for a long distant and stopped / $\mathrm{st}^{\mathrm{j}}$ :ped / under the shadow of trees when I was attending school. During exammination / ezaminai ${ }^{\jmath \jmath} \mathrm{n}$ / periods, when they ring / ring / the bell to start work, I felt happy because I was intelligent in those days. The truth /truf / of the matter is that a time would come when I would be coming $/ \mathrm{k}^{\wedge} \mathrm{ming} /$ to tell the news/ nu:s / of how I attended basic school up to the university / univ ${ }^{\curvearrowright}$ siti / level to my students. 